$03,13,14$

\title{
Полупроводниковые свойства полимерных пленок на основе комплекса никеля с лигандом саленового типа
}

\author{
(ㄱ Ю.А. Положенцева ${ }^{1}$, Е.В. Алексеева², М.П. Карушев \\ ${ }^{1}$ Физико-технический институт им. А.Ф. Иофрфе РАН, \\ Санкт-Петербург, Россия \\ ${ }^{2}$ Санкт-Петербургский государственный университет, \\ Санкт-Петербург, Россия \\ I E-mail: mkarushev@mail.ioffe.ru
}

Поступила в Редакцию 12 июля 2021 г.

В окончательной редакции 9 сентября 2021 г.

Принята к публикации 9 сентября 2021 г.

Комплексы металлов с основаниями Шиффа рассматриваются как перспективные материалы для создания энергозапасающих и фотоэлектрических устройств. В данной работе спектрофотометрическим методом и методом спектроскопии фарадеевского импеданса были изучены полупроводниковые свойства полимерной пленки комплекса никеля с основанием Шиффа саленового типа (поли-Ni( $\left.\left.\mathrm{CH}_{3} \mathrm{O}-\mathrm{Salen}\right)\right)$. Анализ МоттаШоттки показал, что полимерная пленка представляет собой полупроводниковый материал с достаточно узкой шириной запрещенной зоны, высокой плотностью носителей заряда и р-типом проводимости. Методом спектроскопии фарадеевского импеданса установлена лимитирующая стадия реакции фотоэлектровосстановления кислорода - процесс переноса заряда с пленки на молекулярный кислород.

Ключевые слова: основания Шиффа, анализ Мотта-Шоттки, фотоэлектрические устройства, полупроводниковые свойства.

DOI: 10.21883/FTT.2022.01.51832.166

\section{1. Введение}

В настоящее время активно разрабатываются технологии, которые позволили бы широко использовать возобновляемые источники энергии. Среди доступных возобновляемых источников энергии наибольшее внимание привлекает преобразование энергии солнечного света $[1,2]$. Такие фотоэлектрические устройства способны преобразовывать солнечную энергию непосредственно в электрическую или химическую, не причиняя вреда окружающей среде. В основе химического способа преобразования солнечной энергии лежат химические реакции, в ходе которых солнечная энергия запасается, то есть продукты реакции являются более богатыми энергией веществами по сравнению с исходными реагентами. В настоящее время в преобразователях солнечной энергии используют сверхчистые полупроводниковые материалы, что сильно повышает стоимость устройства [3]. В качестве альтернативы широко исследуются органические, неорганические и гибридные полупроводниковые материалы, которые потенциально способны заменить дорогостоящие материалы в фотоэлектрохимических преобразователях солнечной энергии [4,5]. Хотя использование органических материалов обходится дешевле, однако их эффективности пока недостаточно для широкого коммерческого использования [6,7].

Комплексы переходных металлов с основаниями Шиффа обладают высокой стабильностью, электроактивностью, электрической проводимостью и могут рассматриваться в качестве новых полупроводниковых мате- риалов для фотоэлектрических преобразователей [8-10]. Такие полимерные пленки представляют собой сопряженные системы. В них электроны свободно перемещаются по цепи полимера, что обеспечивает эффективный транспорт заряда во всем объеме полимера. При облучении пленки светом, либо в присутствии молекул-акцепторов электронов, пленка становится p-допированной: происходит перенос электронов с поверхности пленки через границу раздела фаз, на поверхности пленки появляется положительный заряд, который компенсируется ионами раствора электролита. Образуется барьер Шоттки. Используя зависимость Мотта-Шоттки, можно оценить полупроводниковые свойства полимерной пленки, такие как тип проводимости, ширина запрещенной зоны, плотность носителей заряда и др.

В настоящей работе были исследованы полупроводниковые свойства полимерной пленки комплекса никеля с лигандом саленового типа поли- $\mathrm{Ni}\left(\mathrm{CH}_{3} \mathrm{O}-\mathrm{Salen}\right)$, структура которого представлена на схеме

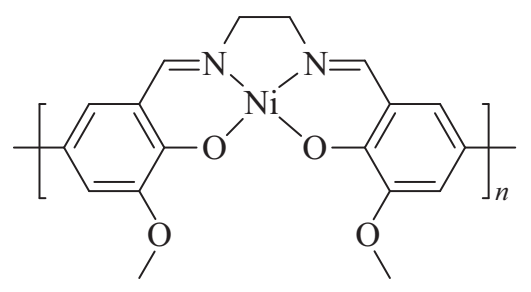

Ранее в работе [11] на примере реакции фотоэлектровосстановления кислорода была показана возможность использования полимерной пленки поли- $\mathrm{Ni}\left(\mathrm{CH}_{3} \mathrm{O}-\mathrm{Salen}\right)$ 
в фотоэлектрокаталических преобразователях энергии. В настоящей работе методом спектроскопии фарадеевского импеданса была установлена лимитирующая стадия процесса фотоэлектровосстановления кислорода. Теория Мотта-Шоттки была использована для описания эмиссии электронов в раствор фонового электролита, насыщенного кислородом.

\section{2. Экспериментальная часть}

Мономер $\mathrm{Ni}\left(\mathrm{CH}_{3} \mathrm{O}\right.$-Salen $)$ был синтезирован по методике [12] из коммерчески доступного альдегида и диамина.

Все электрохимические исследования, в том числе измерения электрохимического фарадеевского импеданca, проводились на потенциостате Bio-Logic (BioLogic Science Instruments, Франция) в трехэлектродной ячейке, рабочий электрод представлял собой стеклоуглеродную (GC)-пластину $\left(2 \mathrm{~cm}^{2}\right)$, вспомогательным электродом служила платиновая фольга. Для электрополимеризации в ацетонитрильном растворе в качестве электрода сравнения использовался неводный $\mathrm{Ag} / \mathrm{Ag}^{+}$электрод MF-2062 (Bio Analytical Systems, USA), заполненный ацетонитрильным раствором, содержащим $0.005 \mathrm{M}$ $\mathrm{AgNO}_{3}$ и $0.1 \mathrm{M} \mathrm{Et}_{4} \mathrm{NBF}_{4}$. Электрод $\mathrm{Ag} / \mathrm{AgCl}$ ( $\mathrm{KCl}$ sat.) использовался для водных растворов. Импедансный отклик системы был проанализирован в координатах Найквиста с использованием программного обеспечения EC-Lab (Bio-Logic, Франция).

Перед каждым экспериментом GC-электрод тщательно шлифовался, промывался изопропиловым спиртом и деионизированной водой, далее высушивался при $120^{\circ} \mathrm{C}$.

Методом электроокислительной полимеризации полимер осаждался на GC-электрод при потенциале $1 \mathrm{~V}$ отн. $\mathrm{Ag} / \mathrm{AgCl}$ из ацетонитрильного раствора, содержащего $0.001 \mathrm{M} \mathrm{Ni}\left(\mathrm{CH}_{3} \mathrm{O}-\right.$ Salen $)$ и $0.1 \mathrm{M} \mathrm{Et}_{4} \mathrm{NBF}_{4}$ в качестве фонового электролита. После пропускания определенного количества электричества $\left(10 \mathrm{mC} / \mathrm{cm}^{2}\right)$ электрод выдерживался при потенциале $0 \mathrm{mV}$ в течение $5 \mathrm{~min}$, чтобы полностью восстановить полимерную пленку, образовавшуюся на его поверхности.

Источником света для фотоэлектрохимических экспериментов был светодиод синего света $(470 \mathrm{~nm})$, мощностью $12 \mathrm{~W}$, расстояние от светодиода до рабочего электрода составляло $5 \mathrm{~cm}$. Мощность излучения составляла около $100 \mathrm{~mW} / \mathrm{cm}^{2}$. Эксперименты по фотоэлектрокаталическому восстановлению кислорода проводились в $0.05 \mathrm{M}$ водном растворе фосфатного буфера $(\mathrm{pH}=6.86)$.

Измерения импеданса проводились в диапазоне частот $0.1 \mathrm{~Hz}-100 \mathrm{kHz}$ при различных потенциалах. Амплитуда переменного напряжения была равна $10 \mathrm{mV}$. При каждом значении потенциала пленка предварительно выдерживалась 2 min для достижения стационарного состояния. Измерения Мотта-Шоттки были выполнены на фиксированной частоте $10 \mathrm{kHz}$ в диапазоне потенциалов $-0.15-0.4 \mathrm{~V}$ (отн. $\mathrm{Ag} / \mathrm{AgCl}$ ) с шагом $50 \mathrm{mV}$. Измерения проводились при отсутствии облучения и при облучении светом как в атмосфере аргона, так и в атмосфере кислорода.

Спектрофотометрические исследования проводились на спектрофотометре СФ-2000 (Россия) в атмосфере аргона. Полимерная пленка осаждалась на стекло, покрытое проводящими оксидами (ITO), спектр пленки регистрировался в ацетонитрильном растворе, содержащем $0.1 \mathrm{M} \mathrm{Et}_{4} \mathrm{NBF}_{4}$ в качестве фонового электролита при потенциале $0 \mathrm{~V}$.

\section{3. Обсуждение результатов}

При облучении полупроводников светом в ряде случаев наблюдается протекание фототока в цепи освещаемой электрохимической ячейки $[13,14]$. При освещении происходит переход электронов на более высокий энергетический уровень, электроны валентной зоны переходят в зону проводимости, оставляя в валентной зоне положительно заряженные дырки. Возможность протекания подобных процессов в пленке поли- $\mathrm{Ni}\left(\mathrm{CH}_{3} \mathrm{O}-\mathrm{Salen}\right)$ была изучена вольтамперометрическим методом.

Вольтамперометрические измерения проводились в диапазоне потенциалов $0.15-0.4 \mathrm{~V}$ в насыщенном кислородом водном растворе фосфатного буфера $(\mathrm{pH}=6.86)$ при облучении светом и при отсутствии облучения. В данном диапазоне потенциалов полимерная пленка поли- $\mathrm{Ni}\left(\mathrm{CH}_{3} \mathrm{O}-\mathrm{Salen}\right)$ была электрохимически стабильна (рис. 1).

В диапазоне потенциалов $0.1-0.4 \mathrm{~V}$ полимерная пленка проявляет электроактивность, на вольтамперограм-

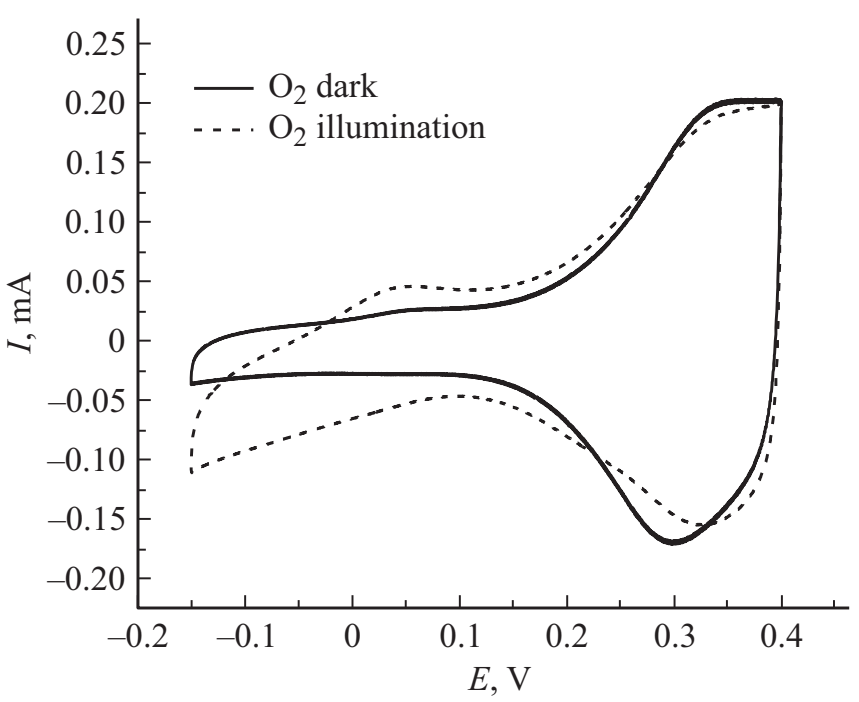

Рис. 1. Циклическая вольтамперограмма полимерной пленки поли-Ni( $\left.\mathrm{CH}_{3} \mathrm{O}-\mathrm{Salen}\right)$, зарегистрированная в растворе насыщенного кислородом фосфатного буфера $(\mathrm{pH}=6.86)$ при облучении и в отсутствии облучения, скорость сканирования электродного потенциала $50 \mathrm{mV} / \mathrm{s}$. 
ме присутствуют волны, характеризующие процессы окисления и восстановления, протекающие в объеме пленки. В отсутствии облучения при потенциалах ниже $0.1 \mathrm{~V}$ полимерная пленка электрохимически неактивна, на вольтамперограмме отсутствуют волны окисления/восстановления полимера, электровосстановление растворенного кислорода на пленке не происходит при данных значениях потенциала, протекающие токи соответствуют фоновым значениям. При облучении светом полимерная пленка начинает вести себя как фотокатод, токи электровосстановления кислорода появляются в диапазоне потенциалов $-0.15-0.4 \mathrm{~V}$, наблюдаемый ток выше по сравнению с электрохимическим откликом пленки в отсутствии облучения, и при смещении потенциала в более отрицательную область эта разница увеличивается.

Облучение фотокатода светом всегда вызывает образование множества электрон-дырочных пар на границе пленка-раствор [14,15]. Однако этот процесс компенсируется обратным процессом - их рекомбинацией. Центрами рекомбинации могут быть, например, дефекты структуры пленки или поверхностные состояния. Благодаря присутствию в растворе растворенного кислорода, удается эффективно разделить эти пары. Адсорбция молекул кислорода на поверхности пленки приводит к частичному переносу заряда с пленки на кислород, что препятствует рекомбинации электрон-дырочных пар, образованных под воздействием света.

Чтобы определить лимитирующую стадию процесса фотоэлектровосстановления кислорода на поверхности полимерной пленки поли- $\mathrm{Ni}\left(\mathrm{CH}_{3} \mathrm{O}-\mathrm{Salen}\right)$, были проведены исследования методом спектроскопии фарадеевского электрохимического импеданса.

На рис. 2 представлены спектры импеданса в координатах Найквиста, полученные при потенциале $0 \mathrm{~V}$ (при потенциале начала процесса фотоэлектрохимического восстановления кислорода). При отсутствии облучения светом годографы, полученные в кислородонасыщенном и деаэрированном растворе, практически совпадают и состоят из линейных участков, соответствующих элементу постоянной фазы, который определяется емкостью двойного электрического слоя на границе раздела пленка-раствор. Такие системы могут быть описаны электрической схемой, состоящей из сопротивления раствора $\left(R_{S}\right)$, последовательно соединенного с элементом постоянной фазы (СРЕ) (схема 1). В условиях облучения годограф видоизменяет свою форму. В составе годографа появляется искаженная полуокружность, которая указывает на протекание фарадеевского процесса, связанного с переносом электрона в пленке и на границе пленка-раствор. Таким образом, в схеме появляется новый элемент - сопротивление переноса заряда $\left(R_{c t}\right)$ (схема 2). Аппроксимация экспериментальных данных и определение параметров выбранных электрических схем производились при минимальном отклонении спектра модели и спектра экспериментальных данных. Рассчитанные параметры приведены в табл. 1.

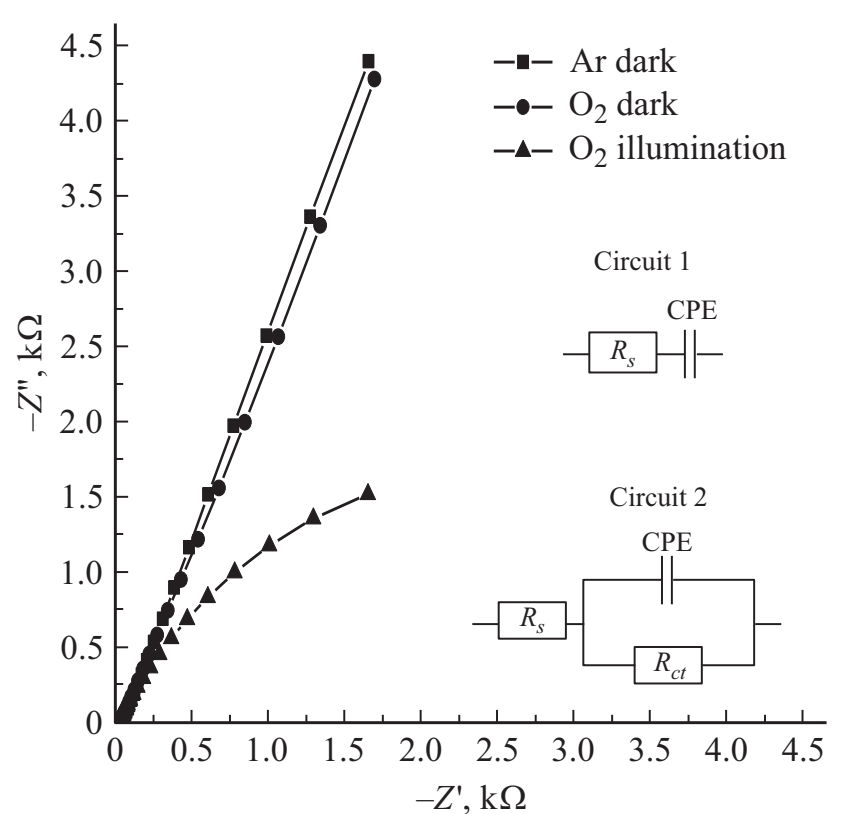

Рис. 2. Годографы импеданса пленки поли-Ni( $\left.\mathrm{CH}_{3} \mathrm{O}-\mathrm{Salen}\right)$ в координатах Найквиста, полученные в растворе фосфатного буфера $(\mathrm{pH}=6.86)$ в присутствии/отсутствии растворенного кислорода при потенциале $0 \mathrm{~V}$, а также в условиях облучения пленки светом и в отсутствии облучения. Также представлены электрические эквивалентные схемы, по которым проводились расчеты основных параметров.

Как видно из табл. 1, с появлением в растворе растворенного кислорода емкость фотоэлектрода возрастает, что связано с адсорбцией молекул кислорода на поверхности пленки и частичным переносом заряда с пленки на кислород. При появлении облучения значение емкости увеличивается практически вдвое по сравнению с темновыми условиями. Это указывает на активную генерацию электрон-дырочных пар на поверхности пленки и эффективное их разделение за счет переноса заряда на адсорбированный кислород. При этом сопротивление переноса заряда достаточно велико, что говорит о том, что именно эта стадия является лимитирующей в процессе фотоэлектровосстановления кислорода.

Важной характеристикой полупроводниковых свойств материала является ширина запрещенной зоны. Для определения ширины запрещенной зоны был использован спектрофометрический способ, спектр пленки в восстановленном состоянии $(0 \mathrm{~V})$ представлен на рис. 3 .

Таблица 1. Расчетные параметры, полученные из годографов импеданса

\begin{tabular}{l|c|c|c|c}
\hline \multicolumn{1}{c|}{ Условия } & $R_{s}, \Omega$ & $\mathrm{CPE}, \mathrm{mF} \cdot \mathrm{s}^{a-1}$ & $a$ & $R_{c t}, \mathrm{k} \Omega$ \\
\hline $\mathrm{Ar}$ в темноте & 32 & 0.378 & 0.87 & - \\
$\mathrm{O}_{2}$ в темноте & 17 & 0.47 & 0.87 & - \\
$\mathrm{O}_{2}$ при облучении & 15 & 0.82 & 0.79 & 7.3
\end{tabular}




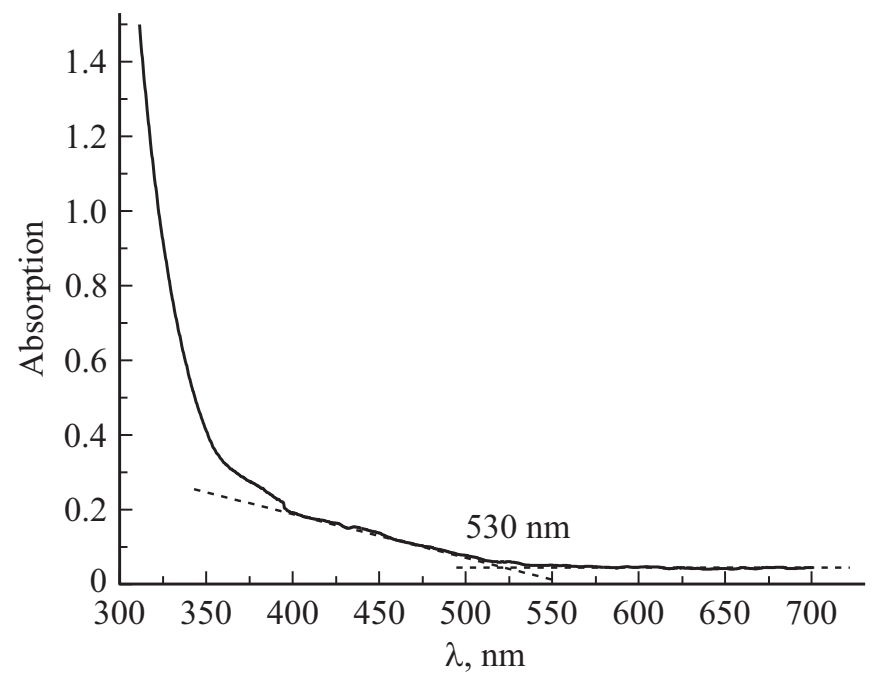

Рис. 3. Спектр пленки поли-Ni( $\left.\mathrm{CH}_{3} \mathrm{O}-\mathrm{Salen}\right)$ на ITO-электроде, зарегистрированный в ацетонитрильном растворе $0.1 \mathrm{M}$ $\mathrm{Et}_{4} \mathrm{NBF}_{4}$ при потенциале $0 \mathrm{~V}$ (восстановленная форма).

Чтобы определить длину волны, при которой в пленке возникают электронные переходы и начинается рост поглощения относительно базовой линии, были проведены вспомогательные линии. Точка пересечения этих линий соответствует длине волны $530 \mathrm{~nm}$, а значение ширины запрещенной зоны составляет $2.3 \mathrm{eV}$. Ширина запрещенной зоны для полупроводников лежит в диапазоне $1-3 \mathrm{eV}$, величина, полученная для пленки, указывает на принадлежность пленки к группе полупроводников.

Чтобы более детально изучить границу раздела пленка-раствор, а также определить потенциал плоских зон и плотность носителей заряда, была получена зависимость Мотта-Шоттки при разных частотах. Известно, что полимерные пленки в присутствии молекулярного кислорода становятся р-допированными [16-18]. В результате перехода электронов через границу раздела фаз поверхность пленки становится положительно заряженной, этот заряд не сосредоточен только на поверхности пленки, а образует некоторую заряженную область вблизи поверхности полупроводника - так называемую область пространственного заряда. На границе раздела пленка-электролит образуется барьер Шоттки, в пленке возникает область обеднения (область пространственного заряда) и происходит изгиб энергетических зон на межфазной границе полупроводника с раствором электролита $[15,19,20]$. Зависимость емкости области пространственного заряда в пленке от потенциала описывается законом Мотта-Шоттки:

$$
\frac{1}{C_{s c}^{2}}=\left(\frac{2}{\varepsilon \varepsilon_{0} A^{2} e N}\right)\left(V-V_{F B}\right),
$$

где $C_{s c}$ - емкость области пространственного заряда, $e-$ заряд электрона, $V$ - значение приложенного потенциала, $\varepsilon$ - диэлектрическая постоянная электродного материала (пленки) $(\varepsilon=2.4[21]), N-$ плотность носителей заряда, $k-$ постоянная Больцмана, $\varepsilon_{0}-$ диэлектрическая проницаемость вакуума, $T-$ абсолютное значение температуры, $V_{F B}$ - потенциал плоских зон, $A$ - площадь электрода.

По угловому коэффициенту линейной части зависимости вольт-фарадной характеристики $2 / \varepsilon \varepsilon_{0} A^{2} e N$, построенной в координатах Мотта-Шоттки $\left(1 / C_{s c}^{2}-V\right)$, можно найти концентрацию носителей заряда $N$, величина потенциала плоских зон определяется линейной экстраполяцией зависимости на ось потенциала.

На рис. 4 приведены зависимости в координатах Мотта-Шоттки для фотоэлектрода поли- $\mathrm{Ni}\left(\mathrm{CH}_{3} \mathrm{O}-\mathrm{Salen}\right)$ в присутствии и отсутствии кислорода, а также в отсутствии облучения и при облучении.

На зависимостях Мотта-Шоттки наблюдаются прямолинейные участки в диапазоне потенциалов $0.1-0.2 \mathrm{~V}$. В рамках теории Мотта-Шоттки это указывает на то, что в зависимости от приложенного к межфазной границе напряжения происходит изменение ее полупроводниковых свойств и переход от одного вида проводимости к другому (от $n$ к $p$ или наоборот). По виду зависимости можно определить тип носителей заряда в пленке ( $p$ или $n$-типа). В данном случае отрицательный наклон кривых зависимости Мотта-Шоттки соответствует проводимости $p$-типа, т.е. основными носителями заряда являются дырки (дырочная проводимость). Это коррелирует с данными вольтамперометрии, где в диапазоне потенциалов $0.1-0.2 \mathrm{~V}$ наблюдается переходная область от окисленного состояния пленки к восстановленному.

Экстраполируя линейные участки зависимостей на ось потенциала, получаем значение потенциала плоских зон. Независимо от условий (присутствие или отсутствие кислорода/облучения) значение потенциала плоских зон

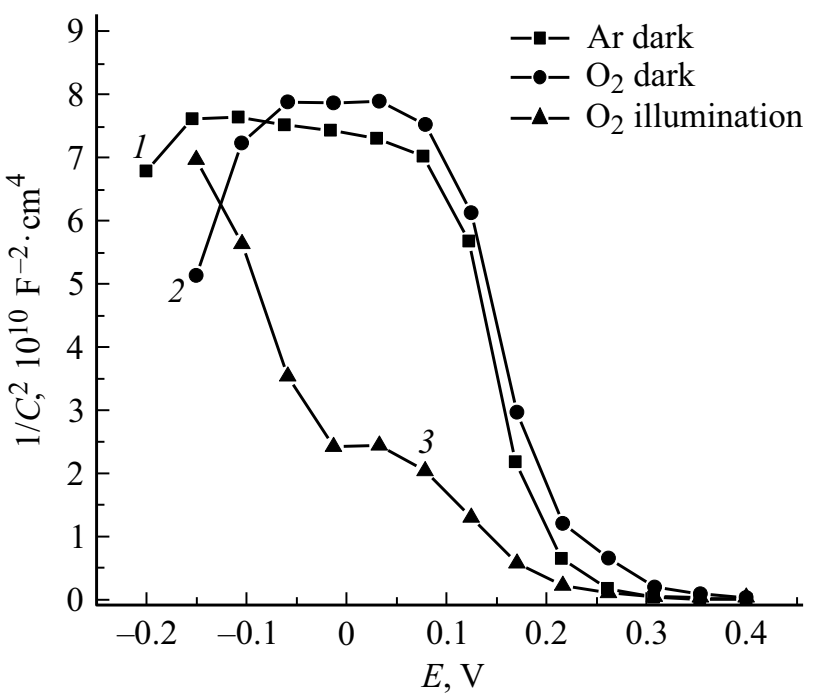

Рис. 4. Зависимости Мотта-Шоттки для фотоэлектрода поли$\mathrm{Ni}\left(\mathrm{CH}_{3} \mathrm{O}-\mathrm{Salen}\right)$, полученные: 1 - при отсутствии кислорода и облучения, 2 - в присутствии кислорода и отсутствии облучения, 3 - в присутствии кислорода и при облучении. Зависимости получены при частоте $10 \mathrm{kHz}$. 
Таблица 2. Результаты анализа Мотта-Шоттки

\begin{tabular}{|c|c|c|c|}
\hline Условия & $\begin{array}{c}\text { Плотность } \\
\text { носителей заряда, } \mathrm{cm}^{-3}\end{array}$ & $\begin{array}{c}\text { Потенциал } \\
\text { плоских зон } V_{f b}, \mathrm{~V}\end{array}$ & $\begin{array}{c}\text { Степень допирования } \\
\text { пленки в диапазоне } \\
0.1-0.2 \mathrm{~V}, \%\end{array}$ \\
\hline $\begin{array}{l}\text { Ar в темноте } \\
\mathrm{O}_{2} \text { в темноте } \\
\mathrm{O}_{2} \text { при облучении }\end{array}$ & $\begin{array}{l}7.8 \cdot 10^{19} \\
1.1 \cdot 10^{20} \\
3.7 \cdot 10^{20}\end{array}$ & $\begin{array}{l}0.20 \\
0.25 \\
0.21\end{array}$ & $\begin{array}{r}2.8 \\
3.9 \\
13.3\end{array}$ \\
\hline
\end{tabular}

находится около $0.2 \mathrm{~V}$ (табл. 2). При потенциале плоских зон толщина области пространственного заряда равна нулю. При смещении потенциала в более положительную область относительно потенциала плоских зон емкость электрода перестает зависеть от приложенного потенциала, при этом пленка находится в допированном (окисленном) состоянии.

Также при отсутствии кислорода и облучения емкость электрода перестает зависеть от потенциала в диапазоне $-0.2-0.1 \mathrm{~V}$ (кривая 1 , рис. 4). Это соответствует полностью восстановленному состоянию пленки, происходит смена типа проводимости и основными носителями заряда являются электроны, а не дырки (электронная проводимость).

В целом кривая вольт-фарадной характеристики пленки в насыщенном кислородом растворе (кривая 2, рис. 4) аналогична кривой, полученной в растворе, не содержащем растворенный кислород (кривая 1, рис. 4). Однако когда в системе появляется кислород, он адсорбируется на активных центрах пленки. Это особенно заметно в области потенциалов ниже $-0.1 \mathrm{~V}$, где наблюдается инверсия зависимости. В этом случае концентрация электронов в поверхностном слое становится выше концентрации дырок, что может быть связано с адсорбцией кислорода на пленке и частичным переносом отрицательного заряда между пленкой и молекулами кислорода.

При облучении фотоэлектрода в атмосфере кислорода на зависимости Мотта-Шоттки появляется второй отрицательный наклон в диапазоне потенциалов $-0.15-0 \mathrm{~V}$ (кривая 3, рис. 4), однако этот наклон нельзя интерпретировать как изменение изгиба зон в полупроводнике. Поскольку двойной электрический слой образован пространственным зарядом в полупроводнике и ионами в растовре, то полный межфазный скачок потенциала будет складываться из скачка потенциала в области пространственного заряда в полупроводнике и скачка потенциала в слое Гельмгольца. В области отрицательных значений потенциала (ниже $0 \mathrm{~V}$ ) происходит очень большое изменение скачка потенциала в слое Гельмгольца, гораздо большее, чем в области пространственного заряда. Это явление называется закреплением уровня Ферми [22-24]. Причиной закрепления уровня Ферми является протекание электрохимической реакции электровосстановления кислорода. При этом изменяется состав окислительно-восстановительной системы в растворе, т.е. уровень Ферми полупроводникового электрода изменяется не электрическим способом, а за счет изменения уровня электрохимического потенциала раствора, находящегося в равновесии с полупроводником. Кроме того, на поверхности пленки могут присутствовать повехностные состояния, заряд которых изменяется в рассматриваемой области потенциалов, что также может приводить к закреплению уровня Ферми. При этом зависимость Мотта-Шоттки по-прежнему представляет собой прямую линию, но наклон ее уже не равен угловому коэффициенту $2 / \varepsilon \varepsilon_{0} e N$, и его нельзя использовать для дальнейших вычислений.

Используя значение углового коэффициента зависимости Мотта-Шоттки, можно рассчитать плотность носителей заряда

$$
N_{D}=\frac{2}{e \varepsilon \varepsilon_{0} \alpha},
$$

где $\alpha-$ угловой коэффициент наклона линейной части зависимости Мотта-Шоттки.

Полученные величины представлены в табл. 2.

Из представленных данных видно, что величина плотности носителей заряда в пленке растет при появлении в растворе растворенного кислорода. Т. е. около $30 \%$ носителей заряда сгенерировано за счет адсорбции кислорода и частичного переноса отрицательного заряда с пленки на кислород. В условиях облучения пленки светом в кислородсодержащей среде плотность носителей заряда в пленке возрастает более чем в 3 раза по сравнению с аналогичными условиями, но в отсутствии облучения. Этот дополнительный заряд был сгенерирован в пленке за счет облучения и полного переноса заряда с пленки на кислород. При этом восстановленная молекула кислорода десорбируется с поверхности пленки и диффундирует в объем раствора. Степень допирования пленки составила единицы процентов в отсутствии облучения и выросла до 13.3\% при облучении.

\section{4. Заключение}

Значение ширины запрещенной зоны для пленки поли$\mathrm{Ni}\left(\mathrm{CH}_{3} \mathrm{O}\right.$-Salen $)$ составило $2.3 \mathrm{eV}$, что указывает на ее принадлежность к группе полупроводниковых материалов. С помощью анализа Мотта-Шоттки были оценены полупроводниковые свойства пленки, показано, что полимерная пленка представляет собой полупроводниковый материал с достаточно узкой шириной запрещенной 
зоны, высокой плотностью носителей заряда и $p$-типом проводимости. Была установлена лимитирующая стадия реакции фотоэлектровосстановления кислорода. Было показано, что лимитирующей стадией реакции является процесс переноса заряда с пленки на молекулярный кислород. Таким образом, полимерную пленку поли$\mathrm{Ni}\left(\mathrm{CH}_{3} \mathrm{O}\right.$-Salen $)$ можно рассматривать в качестве перспективного материала для накопления и преобразования энергии солнечного света, а также для создания фотокатилитических систем на ее основе.

\section{Финансирование работы}

Настоящее исследование выполнено в рамках государственного задания (номер темы 0034-2019-0003) (химический и электрохимический синтез), при поддержке Российского фонда фундаментальных исследований, номер гранта 18-03-00864 (фотокаталитические исследования), Российского фонда фундаментальных исследований, номер гранта 19-29-08026 (электрохимические исследования).

\section{Конфликт интересов}

Авторы заявляют, что у них нет конфликта интересов.

\section{Список литературы}

[1] W. Cao, J. Xue. Energy Environ. Sci. 7, 7, 2123 (2014).

[2] G. Li, R. Zhu, Y. Yang. Nature Photonics 6, 3, 153 (2012).

[3] 3.И. Жураева. Universum: Техн. науки 10, 55, 7 (2018).

[4] M. Skompska. Synth. Met. 160, 1-2, 1 (2010).

[5] G. Yu, A.J. Heeger. J. Appl. Phys. 78, 7, 4510 (1995).

[6] C. Nicolet, D. Deribew, C. Renaud, G. Fleury, C. Brochon, E. Cloutet, L. Vignau, G. Wantz, H. Cramail, M. Geoghegan, G. Hadziioannou. J. Phys. Chem. B 115, 44, 12717 (2011).

[7] P.A. Troshin, R.N. Lyubovskaya, V.F. Razumov. Nanotech. Russ. 3, 5-6, 242 (2008).

[8] Е.А. Смирнова, М.А. Беседина, М.П. Карушев, В.В. Васильев, А.М. Тимонов. ЖФХ 90, 5, 808 (2016).

[9] Т.В. Семенистая, А.В. Щукарев, Г.А. Шагисултанова. ЖПХ 76, 2, 225 (2003).

[10] Т.В. Семенистая, Г.А. Шагисултанова. ЖНХ 48, 4, 602 (2003).

[11] A.S. Konev, M.Y. Kayumov, M.P. Karushev, Y.V. Novoselova, D.A. Lukyanov, E.V. Alekseeva, O.V. Levin. ChemElectroChem 5, 21, 3138 (2018).

[12] P. Pfeiffer, E. Breith, E. Lübbe, T. Tsumaki. Justus Liebig's Ann. Der Chemie 503, 1, 84 (1933).

[13] V.D. Mihailetchi, H.X. Xie, B. de Boer, L.J.A. Koster, P.W.M. Blom. Adv. Funct. Mater. 16, 5, 699 (2006).

[14] A. Iwan, F. Caballero-Briones, M. Filapek, B. Boharewicz, I. Tazbir, A. Hreniak, J. Guerrero-Contreras. Solar Energy 146, 230 (2017).

[15] O. Semenikhin, E. Ovsyannikova, M. Ehrenburg, N. Alpatova, V. Kazarinov. J. Electroanal. Chem. 494, 1, 1 (2000).

[16] C.F. Pereira, A. Olean-Oliveira, D.N. David-Parra, M.F.S. Teixeira. Talanta 190, 119 (2018).
[17] M.S.A. Abdou, F.P. Orfino, Y. Son, S. Holdcroft. J. Am. Chem. Soc. 119, 19, 4518 (1997).

[18] S. Hoshino, M. Yoshida, S. Uemura, T. Kodzasa, N. Takada, T. Kamata, K. Yase. J. Appl. Phys. 95, 9, 5088 (2004).

[19] O.A. Semenikhin, E.V. Ovsyannikova, N.M. Alpatova, Z.A. Rotenberg. J. Electroanal. Chem. 408, 1-2, 67 (1996).

[20] O.A. Semenikhin, M.M.D. Hossain, M.S. Workentin. J. Phys. Chem. B 110, 41, 20189 (2006).

[21] В.Т. Аванесян, М.Ю. Пучков. ФТТ 49, 11, 2088 (2007).

[22] V.N. Brudnyi, S.N. Grinyaev, N.G. Kolin. Phys. B Condens. Matter 348, 1-4, 213 (2004).

[23] G.M. Carroll, A.M. Schimpf, E.Y. Tsui, D.R. Gamelin. J. Am. Chem. Soc. 137, 34, 11163 (2015).

[24] H.Y. Mao, F. Bussolotti, D.-C. Qi, R. Wang, S. Kera, N. Ueno, A.T.S. Wee, W. Chen. Org. Electron. 12, 3, 534 (2011).

Редактор Ю.Э. Китаев 